\title{
In vivo measurements of placental transport and metabolism
}

\author{
BY WILLIAM W. HAY JR \\ Division of Perinatal Medicine, University of Colorado School of Medicine, 4200 East Ninth \\ Avenue, Denver, Colorado 80262, USA
}

In vivo studies of placental transport and metabolism have relied on application of the Fick principle to experimental conditions in large animals, primarily the sheep but including also the goat, cow and horse. The information gained from these studies describes physical properties of the physiological entity known as the 'uteroplacenta' (Meschia et al. 1980). The uteroplacenta is a heterogeneous group of tissues including myometrium, endometrium, chorionic membrane and trophoblast. However, studies of the distribution of uterine and umbilical blood flows and the transplacental diffusion of glucose and oxygen indicate that placental (i.e. trophoblast) metabolism is the major component (over $80 \%$ ) of the metabolic activity of the uteroplacenta (Meschia, 1983). For example, in pregnant sheep in late gestation but before labour contractions, myometrial blood flow (about 3\%) and endometrial blood flow (about 13\%) are relatively small fractions of total uterine blood flow; thus, placental cotyledonary blood flow (about 84\%) determines that uteroplacental metabolism is largely placental (Makowski et al. 1968). In order to apply the Fick principle to measure in vivo net transfer and net uptake or production rates of metabolic substrates by the uteroplacenta, pregnant animals are prepared surgically with the following: catheters for blood sampling are placed into a maternal artery (usually the femoral), a large uterine vein, one fetal artery (usually the femoral which carries blood of the same composition as that perfusing the umbilical artery), and the umbilical vein (via direct insertion); a catheter for infusion of test substances or 'tracers' is placed into a fetal femoral vein (Meschia et al. 1967a,b; Fig. 1). In fetuses too small for direct vascular catheterization, small cotyledonary branches can be catheterized with very narrow catheters that are advanced into larger umbilical venous and arterial vessels; in this case, the infusion catheter is inserted into a cotyledonary vein supplying the other umbilical vein (Bell et al. 1987; Fig. 2). Test substances that are infused into the fetus to measure umbilical and uterine blood flows must be relatively inert, highly permeable to all fetal and uteroplacental tissues, and demonstrate maximum flow-limited clearance by the placenta; i.e. differing physicochemical properties, including permeabilities, are not determinants of uteroplacental transfer (Meschia et al. 1967a,b). Commonly used test substances include antipyrine, tritiated water and ethanol which, as shown in Table 1 , have virtually identical placental clearances in spite of marked differences in physicochemical properties (Meschia et al. 1967a; Wright \& Diamond, 1969; Naccache \& Sha'afi, 1973; Bissonnette et al. 1979; Bonds et al. 1980).

To perform a physiological study of the uteroplacenta, at time zero a test substance is infused into the fetal femoral vein catheter at a known constant rate. After a period of equilibration, usually $60-70 \mathrm{~min}$, a steady state is achieved in which the rate of testsubstance infusion is balanced equally by its rate of utilization or metabolism, its rate of accumulation in the fetus, placenta and mother, and its transplacental diffusion rate. This steady-state provides relatively linear changes in test-substance concentration in the 


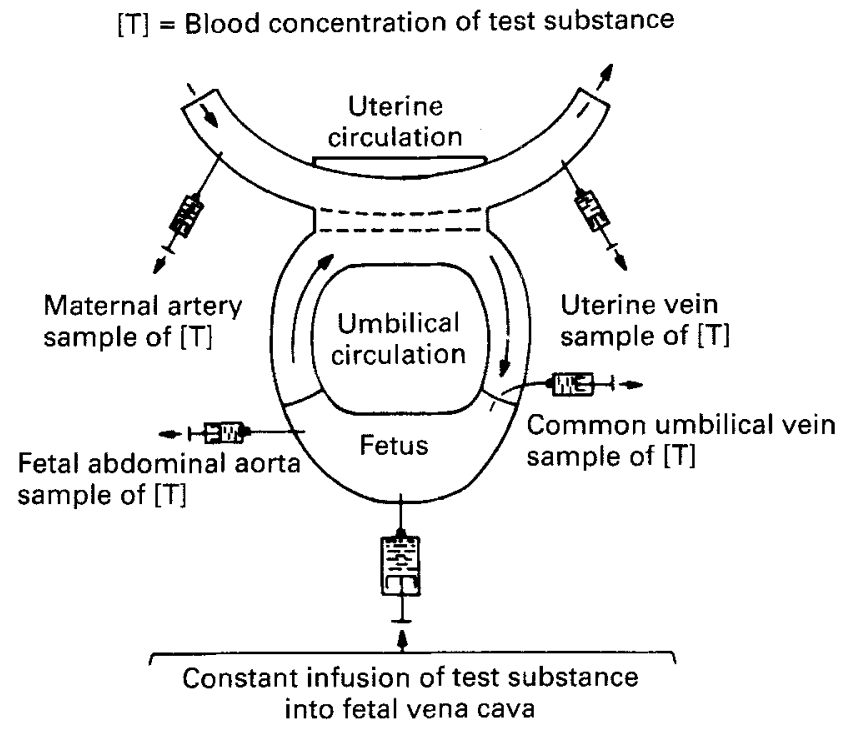

Fig. 1. Schematic representation of the methodology used in the study of uteroplacental transfer and metabolism in vivo. Reproduced with permission of Federation Proceedings and the authors (Meschia et al. 1980).

Table 1. A comparison of physicochemical properties of ${ }^{3} \mathrm{H}_{2} \mathrm{O}$, antipyrine and ethanol, and their placental clearances (adapted from Battaglia \& Meschia, 1986)

\begin{tabular}{|c|c|c|c|c|}
\hline Test substance ... & ${ }^{3} \mathrm{H}_{2} \mathrm{O}$ & Ethanol & Antipyrine & References \\
\hline Molecular weight & 19 & 46 & 188 & \\
\hline Partition coefficient (diethyl ether-water) & 0.003 & $0 \cdot 26$ & 0.073 & Bissonnette et al. (1979) \\
\hline Permeability, erythrocytes $(\mathrm{cm} / \mathrm{s}) \times 10^{-5}$ & 915 & $8 \cdot 8$ & & Naccache \& Sha'afi (1973) \\
\hline Reflection coefficient, gall bladder & - & $0 \cdot 050$ & $0 \cdot 370$ & Wright \& Diamond (1969) \\
\hline $\begin{array}{l}\text { Placental clearance ratio, sheep } \\
\left({ }^{3} \mathrm{H}_{2} \mathrm{O} \text { : test substance }\right)\end{array}$ & $1 \cdot 0$ & $1 \cdot 09$ & $1 \cdot 02$ & $\begin{array}{l}\text { Bonds et al. (1980); } \\
\text { Meschia et al. }(1967 a)\end{array}$ \\
\hline
\end{tabular}

blood sampled simultaneously from the fetal artery, umbilical vein, maternal artery and uterine vein and constant test-substance concentration differences between the fetal artery and umbilical vein, the uterine vein and uterine artery, and the fetal artery and uterine artery (Fig. 3). Several sets of blood samples are collected over 30-40 min; the increase in test-substance concentration over time (slope) plus the distribution volume in fetal body water are used to calculate the test-substance rate of accumulation. Testsubstance metabolism must be calculated separately, although its value relative to transplacental diffusion rate for test substances such as antipyrine, ${ }^{3} \mathrm{H}_{2} \mathrm{O}$ and ethanol is very small.

Transplacental diffusion rate is calculated as the difference between test-substance infusion rate and the rate of test-substance accumulation plus metabolism. When the transplacental diffusion rate is divided by the umbilical arterio-venous blood concentration difference, umbilical blood flow is calculated; when the transplacental diffusion 


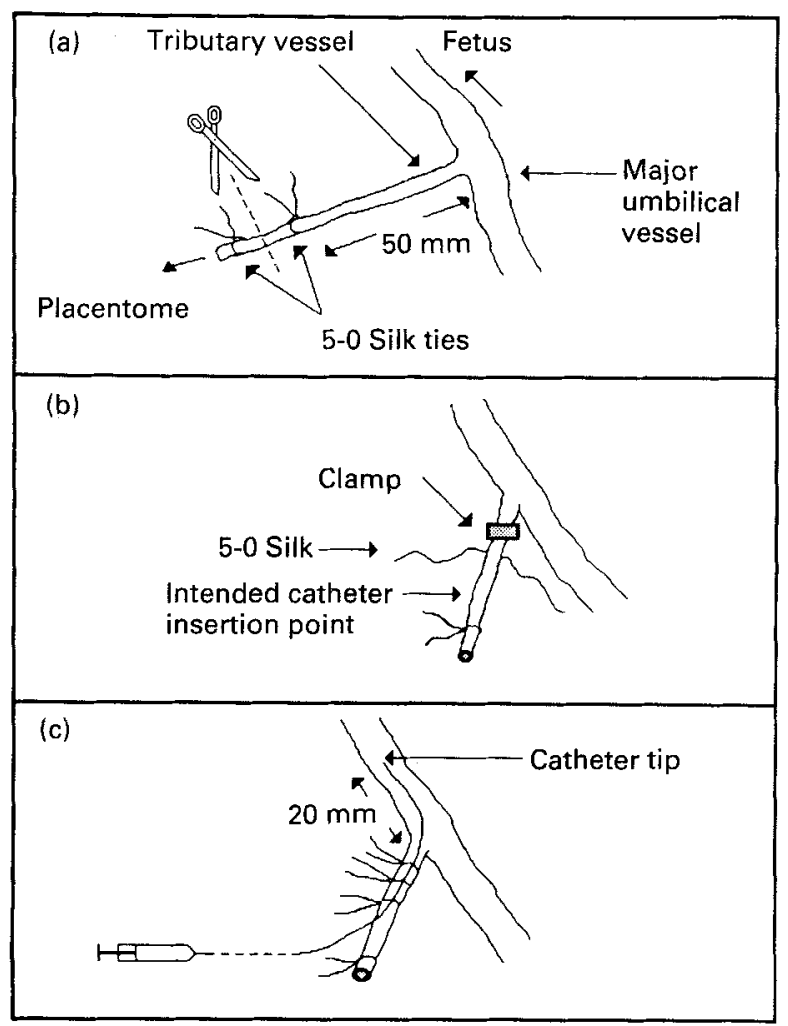

Fig. 2. Schematic representation of the method for placing umbilical venous and arterial catheters into placental cotyledonary vessels that are tributaries to major umbilical vessels in the $65-75 \mathrm{~d}$ mid-gestation sheep fetus: (a) location of silk ties before severing the tributary (which allows placement of the catheter free of impingement by the cotyledon), (b) location of vascular clamp and silk tie before cutting the vessel, (c) location of catheter and securing of ties after insertion. Reproduced with permission of Perinatology Press and the authors (Bell et al. 1987).

rate is divided by the uterine veno-arterial blood concentration difference, uterine blood flow is calculated (Table 2).

Once umbilical and uterine blood flows are determined, they can be used according to the Fick principle to calculate net uptake of a substrate by the entire uterus (conceptus), the fetus, and, by difference, the uteroplacenta (Table 3). These uptake rates are net rates and, thus, according to the law of conservation of matter, represent true consumption (or production) rates. Examples of information obtained in late-gestation pregnant sheep for net fluxes of $\mathrm{O}_{2}$, glucose and lactate are shown in Table 4 (Meschia et al. 1980). Note that for lactate uterine uptake is negative, that is, lactate is produced by the uteroplacenta and delivered in net into both umbilical and uterine circulations.

Radioactive and stable isotopic tracers of various metabolic substrates, also, have been used to study placental metabolism in vivo (Hay \& Sparks, 1987). For example, $\left[{ }^{14} \mathrm{C}\right]-$ and $\left[{ }^{3} \mathrm{H}\right]$ glucose have been infused into maternal and fetal circulations demonstrating that the placenta is bidirectionally permeable to glucose and that placental glucose consumption (quantified by application of the Fick principle for tracer glucose just as for 


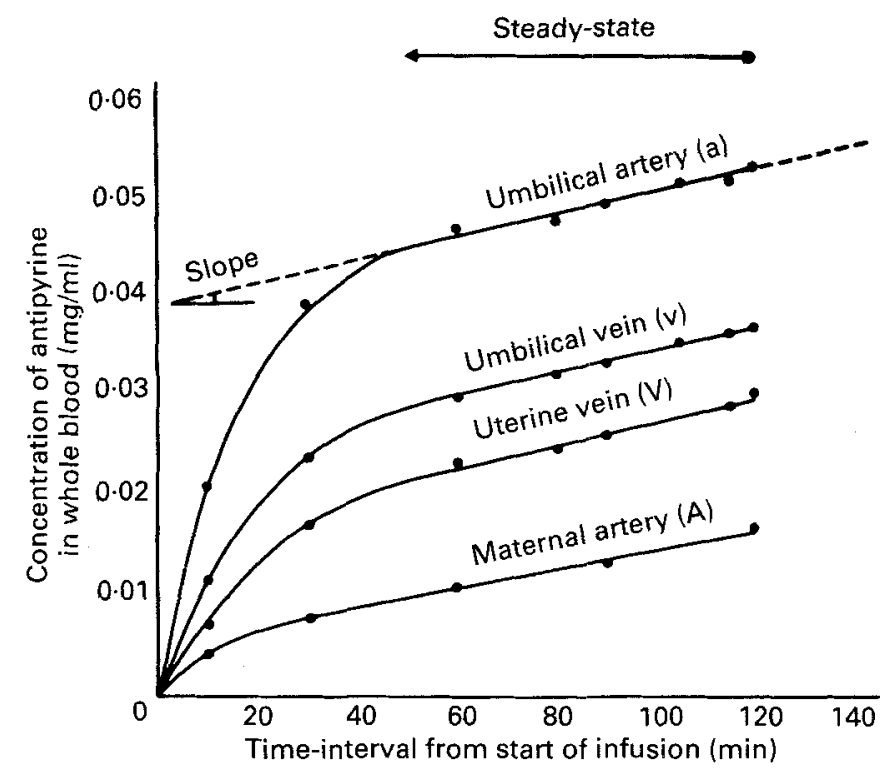

Fig. 3. Concentrations of antipyrine in fetal and maternal blood during the continuous infusion of antipyrine into the femoral vein of a near-term fetal lamb. Infusion rate $10 \mathrm{mg} / \mathrm{min}$, fetal weight $3750 \mathrm{~g}$, fetal body water $3000 \mathrm{ml}$. Reproduced with permission of Appleton-Century-Crofts and the author (Meschia, 1976).

Table 2. Equations used to calculate umbilical and uterine blood flows

1. Umbilical flow $=\frac{\text { transplacental diffusion rate of test molecule }}{\text { umbilical arterio-venous difference of test molecule }}$
2. Uterine flow $=\frac{\text { transplacental diffusion rate of test molecule }}{\text { uterine veno-arterial difference of test molecule }}$
$\begin{aligned} & \text { Transplacental diffusion rate of test molecule }=\text { infusion rate }- \text { rate of metabolism }- \text { rate of } \\ & \text { transplacental diffusion, and rate of accumulation is slope of } \\ & \text { fetal arterial concentration }\end{aligned}$
time

Table 3. Fick principle calculations of net uptake of a substance $(X)$ by the uterus (uterine) fetus (umbilical), and uteroplacenta

1. Uterine uptake of $\mathrm{X}=$ uterine blood flow $\times$ blood arterio-venous concentration of $\mathrm{X}$

2. Umbilical uptake of $X=$ umbilical blood flow $\times$ blood veno-arterial concentration difference of $X$

3. Uteroplacental uptake of $X=$ uterine uptake of $X-$ umbilical uptake of $X$ 
Table 4. Numerical example of the application of the Fick principle to the calculation of oxygen, glucose, and lactate net fluxes from values in late-gestation pregnant sheep (adapted from Battaglia \& Meschia, 1986; Hay \& Meznarich, 1989)

(Experimental values of uterine blood flow $1585 \mathrm{ml} / \mathrm{min}$, umbilical blood flow $790 \mathrm{ml} / \mathrm{min}$ )

\begin{tabular}{lcccc}
\hline \hline & Maternal artery & Uterine vein & Umbilical vein & Umbilical artery \\
\hline $\mathrm{O}_{2}(\mu \mathrm{mol} / \mathrm{ml})$ & 6.05 & 4.67 & 5.40 & 1.00 \\
Glucose $(\mu \mathrm{mol} / \mathrm{ml})$ & 2.76 & 2.60 & 1.19 & 1.07 \\
Lactate $(\mu \mathrm{mol} / \mathrm{ml})$ & 0.67 & 0.71 & 1.70 & 1.56 \\
\hline \hline
\end{tabular}

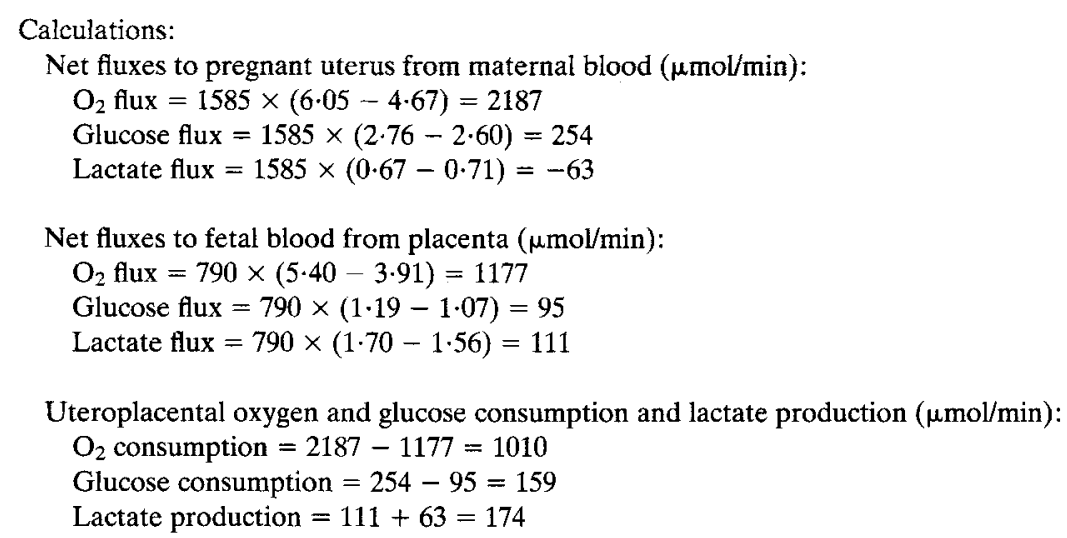

glucose) includes glucose molecules derived from both fetal and maternal plasma glucose pools (Hay et al. 1981). Because of these conditions, tracer models which do not account for net placental glucose and tracer glucose consumption lump together portions of uteroplacental glucose metabolism with maternal and fetal rates of glucose metabolism (Hay et al. 1984). Such two-pool (maternal-fetal) rather than three-pool (maternalplacental-fetal) models thereby overestimate maternal and fetal glucose metabolic rates and ignore or mask the very significant contribution of placental glucose metabolism to maternal metabolism and the production of the maternal-fetal glucose concentration gradient that drives glucose from the maternal to the fetal plasma. Tracer methods, also, have been used to identify pathways and products of placental metabolism. For example, $\left[{ }^{14} \mathrm{C}\right]$-glucose infused into either maternal or fetal sheep results in ${ }^{14} \mathrm{C}$-labelling of carbon dioxide, fructose, and lactate. By calculating the net uptake of the glucose tracer by the placenta (Fick principle calculations), and measuring net $\left[{ }^{14} \mathrm{C}\right]$ lactate, and $\left[{ }^{14} \mathrm{C}\right]$ fructose production by the placenta, one can estimate the relative contribution of glucose- $\mathrm{C}$ to these specific metabolic fluxes (DiGiacomo \& Hay, 1989).

There are several additional advantages to this in vivo methodology. First, information is provided from conscious, healthy, unstressed animals in which placental function is normal or regulated to some desired but known condition. As shown in Fig. 4, grossly aberrant values for umbilical venous and arterial plasma amino acid concentrations are obtained from animals that are stressed by surgical intervention and anaesthesia (Lemons et al. 1976; Smith et al. 1977). Unless in vitro methodology provides for normal placental conditions, similar discrepant values for placental handling of metabolic 


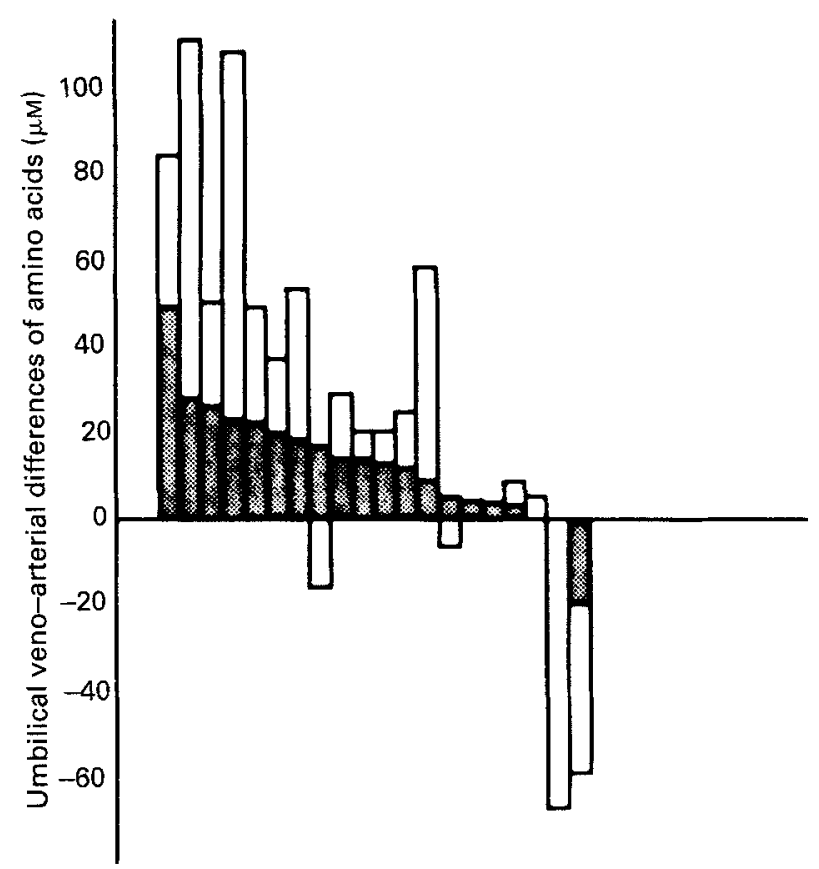

Fig. 4. A comparison of umbilical veno-arterial differences of amino acids reported in two studies on fetal lambs, one in chronically catheterized animals (Lemons et al. 1976) and one in animals studied acutely (Smith et al. 1977) for glutamine, glycine, valine, alanine, leucine, arginine, threonine, serine, asparagine, isoleucine, tyrosine, phenylalanine, lysine, citrulline, ornithine, 3-methyl histidine, histidine, taurine, aspartate and glutamate respectively. Reproduced with permission of Academic Press and the authors (Battaglia \& Meschia, 1986).

substrates may result. Second, measurements of blood flow through the uterine and umbilical circulation are obtained and the impact of their absolute and relative magnitudes and their composition (e.g. erythrocyte concentration) on placental metabolism assessed (Wilkening et al. 1982). Third, studies can be conducted over large portions of gestation during which fetal and placental development change considerably. Fourth, placental-fetal and placental-maternal interactions can be studied directly; this is vitally important, given that much of placental function is directly dependent on fetal and maternal factors such as the supply of hormones, metabolic substrates, growth factors, etc. Finally, conditions in the plasma of the maternal or fetal circulations (for example, concentrations of nutrient substrates, hormones, and metabolic inhibitors) can be changed experimentally and their consequences regarding placental transport and metabolism quantified.

There are several obvious limitations to in vivo measurements of placental function. First, as discussed earlier, measurements include some tissues of the uterus that are not strictly trophoblast, although most studies indicate that this is a relatively minor quantitative problem. Second, in vivo methodology is invasive and, thus, for obvious technical and ethical reasons cannot, for the most part, be conducted in pregnant women. Recent successful development of direct percutaneous umbilical blood sampling combined with stable-isotope infusions in pregnant women have, however, made such 
methodology more feasible for clinical research. Finally, measurement of transfer and metabolic rates by the placenta, in vivo or in vitro, is limited to those substances which are sufficiently changed in concentration across the umbilical circulation or the uterine circulation to significantly exceed the accuracy of their concentration measurement in the maternal or fetal blood. For example, certain amino acids have extraction ratios by the placenta much greater than their measurement accuracy (e.g. for leucine, the measurement accuracy coefficient is $3 \%$ and the umbilical extraction coefficient is $11 \%$ ). This is not the case for other amino acids (e.g. for leucine, the measurement accuracy coefficient is $3 \%$ but the umbilical extraction coefficient is $0-0.5 \%$; Battaglia \& Meschia, 1986). In general, extraction coefficients are smaller on the uterine side of the placenta, given the two- to threefold higher uterine blood flow-rate.

The author acknowledges support by National Institutes of Health grants nos. DK35836, HD20761 and HD00781.

\section{REFERENCES}

Battaglia, F. C. \& Meschia, G. (1986). An Introduction to Fetal Physiology, p. 104. Orlando, Florida: Academic Press.

Bell, A. W., Battaglia, F. C. \& Meschia, G. (1987). Methods for chronic studies of circulation and metabolism in the sheep conceptus at 70-80 days gestation. In Animal Models in Fetal Medicine, vol. 6, pp. 37-54 [P. W. Nathanielsz, editor]. Ithaca, NY: Perinatology Press.

Bissonnette, J. M., Cronan, J. Z., Richards, L. L. \& Wickham, W. K. (1979). Placental transfer of water and nonelectrolytes during a simple circulatory passage. American Journal of Physiology 236, C47-C52.

Bonds, D. R., Anderson, S. \& Meschia, G. (1980). Transplacental diffusion of ethanol under steady state conditions. Journal of Developmental Physiology 2, 409-416.

DiGiacomo, J. E. \& Hay, W. W. Jr (1989). Contribution of fructose and lactate to calculation of fetal glucose oxidation rate. FASEB Journal 3, A1138, Abstr. 5299.

Hay, W. W. Jr \& Meznarich, H. K. (1989). Effect of maternal glucose concentration on uteroplacental glucose consumption and transfer in pregnant sheep. Proceedings of Society for Experimental Biology and Medicine $190,63-69$.

Hay, W. W. Jr \& Sparks, J. W. (1987). Tracer methods for studying fetal metabolism in vivo. In Animal Models in Fetal Medicine, vol. 6, pp. 133-177 [P. W. Nathanielsz, editor]. Ithaca, NY: Perinatology Press.

Hay, W. W. Jr, Sparks, J. W., Battaglia, F. C. \& Meschia, G. (1984). Maternal-fetal glucose exchange: The necessity of a three pool model. American Journal of Physiology 246, E528-E534.

Hay, W. W. Jr, Sparks, J. W., Quissell, B. J., Battaglia, F. C. \& Meschia, G. (1981). Simultaneous measurements of umbilical uptake fetal utilization rate, and fetal turnover of glucose. American Journal of Physiology 240, E662-E668.

Lemons, J. A., Adcock, E. W. III, Jones, M. D. Jr, Naughton, M. A. \& Meschia, G. (1976). Umbilical uptake of amino acids in the unstressed fetal lamb. Journal of Clinical Investigation 58, 1428-1434.

Makowski, E. L., Meschia, G., Droegemueller, W. \& Battaglia, F. C. (1968). Distribution of uterine blood flow in the pregnant sheep. American Journal of Obstetrics and Gynecology 101, 409-412.

Meschia, G. (1976). Physiology of transplacental diffusion. In Obstetrics and Gynecology Annual, pp. 21-38 [R. M. Wynn, editor]. New York: Appleton-Century-Crofts.

Meschia, G. (1983). Circulation to female reproductive organs. In Handbook of Physiology. The Cardiovascular System III, pp. 241-269 [J. T. Shepherd and F. M. Abboud, editors]. Bethesda, Maryland: American Physiology Society.

Meschia, G., Battaglia, F. C. \& Bruns, P. D. (1967a). Theoretical and experimental study of transplacental diffusion. Journal of Applied Physiology 22, 1171-1178.

Meschia, G., Battaglia, F. C., Hay, W. W. Jr \& Sparks, J. W. (1980). Utilization of substrates by the ovine placenta in vivo. Federation Proceedings 39, 245-249.

Meschia, G., Cotter, J. R., Makowski, E. L. \& Barron, D. H. (1967b). Simultaneous measurement of uterine and umbilical blood flows and oxygen uptakes. Quarterly Journal of Experimental Physiology 52, 1-18. 
Naccache, P. \& Sha'afi, R. I. (1973). Patterns of nonelectrolyte permeability in human red blood cell membrane. Journal of General Physiology 62, 714-736.

Smith, R. M., Jarrett, I. G., King, R. A. \& Russell, G. R. (1977). Amino acid nutrition of the fetal lamb. Biology of Neonate 31, 305-310.

Wilkening, R. B., Anderson, S., Martensson, L. \& Meschia, G. (1982). Placental transfer as a function of uterine blood flow. American Journal of Physiology 242, H429-H436.

Wright, E. M. \& Diamond, J. M. (1969). Patterns of nonelectrolyte permeability. Proceedings of the Royal Society of London 172, 227-271. 